\title{
Effect of Ionising Radiation on Potassium Pentacyanonitrosylruthenate(II): an Electron Spin Resonance Study
}

\author{
Ney V. Vugman $*^{a}$, Nelson M. Pinhal ${ }^{a}$, Cristina M. P. dos Santos ${ }^{b}$, \\ Roberto B. Faria ${ }^{b}$ and Hélio S. de Amorim ${ }^{a}$ \\ ${ }^{\mathrm{a}}$ Departamento de Física dos Sólidos, Instituto de Física, Universidade \\ Federal do Rio de Janeiro, 21945-970, Rio de Janeiro - RJ, Brazil \\ bepartamento de Química Inorgânica, Instituto de Química, Universidade \\ Federal do Rio de Janeiro, 21949-900 Rio de Janeiro, RJ, Brazil
}

\begin{abstract}
O sal pentacianonitrosilrutenato(II) de potássio, em forma amorfa, foi sintetizado e caracterizado por espectroscopias UV, IR, difração de raios X e análise termogravimétrica. Amostras irradiadas por raios X revelam, por espectroscopia de Ressonância Paramagnética Eletrônica, a presença de complexos paramagnéticos de rutênio (I) e de radicais $\mathrm{NO}_{2}$. Os parâmetros do hamiltoniano de spin medidos para o complexo $\left[\mathrm{Ru}(\mathrm{CN})_{5} \mathrm{NO}\right]^{3-}\left(\mathrm{g}_{\perp}=2.0064, \mathrm{~A}_{\perp}\left({ }^{14} \mathrm{~N}\right)=60.7 \mathrm{MHz}, \mathrm{g}_{\|}=1.999\right.$, $\left.\mathrm{A}_{\|}(14 \mathrm{~N})=77.3 \mathrm{MHz}\right)$ indicam uma captura eletrônica em um orbital molecular $\pi^{*}$ do grupo nitrosil com a participação de orbitais $\mathrm{d}_{\mathrm{xz}}$ and $\mathrm{d}_{\mathrm{yz}}$ do rutênio, como recentemente previsto por cálculos teóricos. Íons de prata, presentes como impurezas oriundas da rota sintética, são reduzidos a $\operatorname{Ag}(0)$ durante a irradiação e interagem com quatro nitrogênios equivalentes em um sítio distorcido, originando um espectro de RPE anisotrópico.
\end{abstract}

Amorphous potassium pentacyanonitrosylruthenate (II) was synthesized and characterized by UV, IR, X-ray diffraction and thermogravimetric analysis. Electron Spin Resonance spectroscopy reveals the presence of paramagnetic ruthenate (I) complexes and $\mathrm{NO}_{2}$ radicals in the X-irradiated diamagnetic salt. Spin-hamiltonian parameters of the $\left[\mathrm{Ru}(\mathrm{CN})_{5} \mathrm{NO}\right]^{3-}$ complex $\left(\mathrm{g}_{\perp}=2.0064\right.$, $\mathrm{A}_{\perp}\left({ }^{14} \mathrm{~N}\right)=60.7 \mathrm{MHz}, \mathrm{g}_{\|}=1.999, \mathrm{~A}_{\|}\left({ }^{14} \mathrm{~N}\right)=77.3 \mathrm{MHz}$ ) support an electron capture in a $\pi^{*}$ molecular orbital of the nitrosyl group mixed with $\mathrm{d}_{\mathrm{xz}}$ and $\mathrm{d}_{\mathrm{yz}}$ ruthenium orbitals as recently predicted by theoretical calculations. Silver ions, present as impurities, are reduced to $\mathrm{Ag}(0)$ by $\mathrm{X}$-irradiation and coordinate to four magnetically equivalent nitrogens in a distorted site, giving rise to a well resolved anisotropic ESR powder spectrum.

Keywords: pentacyanonitrosylruthenate, ESR, radiation damage

\section{Introduction}

Diamagnetic transition metal complexes can render paramagnetic species when submitted to ionising radiation or to electrochemical process. Among the many species that have been characterized by Electron Spin Resonance (ESR), the pentacyanonitrosylferrate(II) complex (nitroprusside salt) is, probably, the most extensively studied. Species like $\left[\mathrm{Fe}(\mathrm{CN})_{5} \mathrm{NOH}\right]^{2-}$ and $\left[\mathrm{Fe}(\mathrm{CN})_{5} \mathrm{NO}\right]^{3-}$, generated by electrochemical reduction of a solution of $\mathrm{Na}_{2}\left[\mathrm{Fe}(\mathrm{CN})_{5} \mathrm{NO}\right]$ in dimethylformamide (DMF), were identified by ESR spectroscopy 1-3. Single crystals or powder sodium nitroprusside gamma- or electron-irradiated at different temperatures were

*e-mail: ney@if.ufrj.br submitted to ESR analysis and in all situations the presence of a $\left[\mathrm{Fe}(\mathrm{CN})_{5} \mathrm{NO}\right]^{3-}$ species was confirmed 4,5 . Two $\mathrm{d}^{7}$ centers are assigned in the ESR spectra of alkali and alkaline earth pentacyanonitrosylferrate (II) salts, gamma-irradiated at $77 \mathrm{~K}:\left[\mathrm{Fe}(\mathrm{CN})_{4} \mathrm{NO}\right]^{2-}$, with axial symmetry, and $\left[\mathrm{Fe}(\mathrm{CN})_{5} \mathrm{NO}\right]^{3-}$, with rhombic symmetry6. The presence of different cations and/or the presence of hydration water in these species influences the measured $g$ and $A$ values.

On the other hand, the $4 \mathrm{~d}$ analogous complex, $\left[\mathrm{Ru}(\mathrm{CN})_{5} \mathrm{NO}\right]^{3-}$ has not been studied in detail. Attempts to produce the paramagnetic complex by electrochemical reduction 7 lead to a broad unresolved ESR signal. In this work we present a detailed ESR study of potassium pentacyanonitrosyl-ruthenate(II) salt submitted to X-ray irradiation at $298 \mathrm{~K}$ and $77 \mathrm{~K}$. 


\section{Experimental}

Reagents $\mathrm{RuCl}_{3} \cdot x \mathrm{H}_{2} \mathrm{O}$ (Aldrich), $\mathrm{KCN}$ (Vetec), $\mathrm{KOH}$, $\mathrm{MeOH}, \mathrm{Et}_{2} \mathrm{O}, \mathrm{Br}_{2}, \mathrm{AgNO}_{3}, \mathrm{~K}_{2} \mathrm{CO}_{3}$ and $\mathrm{KCl}$ (Grupo Química) were used without further purification. Water was distilled and further deionized.

Ultraviolet-visible spectra were obtained using a HP 8452A diode array spectrophotometer. Infrared spectra were obtained using a dispersive 467 Perkin-Elmer spectrophotometer for the 4000 to $500 \mathrm{~cm}^{-1}$ region and a 2000 FTIR Perkin-Elmer spectrophotometer for the 600 to $30 \mathrm{~cm}^{-1}$ region. The TGA analysis used a Shimadzu TGA-50H detector.

Powdered samples of $\mathrm{K}_{2}\left[\mathrm{Ru}(\mathrm{CN})_{5} \mathrm{NO}\right] . \mathrm{H}_{2} \mathrm{O}$ were irradiated with $\mathrm{X}$-rays produced by a tungsten tube operating at $80 \mathrm{kV}, 5 \mathrm{~mA}$ current. Irradiation times were 30 and $60 \mathrm{~min}$, at room and liquid nitrogen temperature. ESR spectra were recorded, in continuous wave, on a Bruker ESP-380e CW/FT spectrometer at X-band frequency and on a Bruker ER-420 spectrometer at Q-band frequency. Attempts to detect pulsed ESR were unsuccessful: no FID and no spin echo were detected, at temperatures down to liquid helium.

\section{Synthesis and characterization}

The starting compound, $\mathrm{K}_{4}\left[\mathrm{Ru}(\mathrm{CN})_{6}\right]$, was obtained using Krause and Violette procedure ${ }^{8}$. In this process, the amount of KCN was increased by $20 \%$ to compensate for the fast decomposition observed for this reagent.

The synthesis of the potassium pentacyanonitrosylruthenate (II) salt was carried out following the procedure described by Butler et al. ${ }^{9}$. The $\mathrm{pH}$ was adjusted carefully to 6.0 with a $2 \% \mathrm{~K}_{2} \mathrm{CO}_{3}$ solution. The $\mathrm{K}_{2} \mathrm{CO}_{3}$ solution was added in small amounts under magnetic stirring to avoid the formation of local basic regions inside the solution, which would result in the formation of an unwanted dark precipitate. This unknown dark precipitate is probably formed from the reaction of $\left[\mathrm{Ru}(\mathrm{CN})_{5} \mathrm{NO}^{2-}\right.$ with $\mathrm{OH}^{-}$ in the same way as the yellow $\left[\mathrm{Ru}(\mathrm{CN})_{5} \mathrm{NO}_{2}\right]^{4-}$ is formed together with a pink-red unknown product when the former is placed in the presence of $\mathrm{OH}^{-}$or $\mathrm{SH}^{-} .9$

The infrared spectra of $\mathrm{K}_{2}\left[\mathrm{Ru}(\mathrm{CN})_{5} \mathrm{NO}\right] . \mathrm{H}_{2} \mathrm{O}$ in $\mathrm{KBr}$ and polyethylene are in agreement with those obtained by Olabe et al. ${ }^{10}$ for the $\mathrm{Na}_{2}\left[\mathrm{Ru}(\mathrm{CN})_{5} \mathrm{NO}\right]$ complex in mineral oil. The ultraviolet-visible spectrum, obtained in aqueous solution, presents one band with $\lambda_{\max }=440 \mathrm{~nm}$, in agreement with the value related by Guenzburger et al. ${ }^{11}$ of $444.4 \mathrm{~nm}$. X-ray diffration analysis reveals the amorphous nature of the complex and the presence of $\mathrm{KCl}$ and $\mathrm{AgCl}$ crystals in the synthesized sample. Thermogravi- metric measurements clearly indicate the presence of one crystallization water. The synthesized sample is therefore to amorphous $\mathrm{K}_{2}\left[\mathrm{Ru}(\mathrm{CN})_{5} \mathrm{NO}\right] \cdot \mathrm{H}_{2} \mathrm{O}$.

\section{Results and Discussion}

Room temperature irradiation of synthesized sample produces several paramagnetic species. When measured at room temperature, ESR spectra exhibit a $12.7 \mathrm{MHz}$ linewidth intense triplet at $\mathrm{g} \cong 2.0064$, a single line $22.4 \mathrm{MHz}$ wide at $g$ $=2.0005$ and other weaker lines. This central spectrum is flanked by multiplets distant of about 300 Gauss from its centre.

\section{The $\left[\mathrm{Ru}(\mathrm{CN})_{5} \mathrm{NO}\right]^{3-}$ species}

The intense triplet (Figure 1b) is attributed to the interaction of the unpaired electron with a nitrogen nucleus of a nitrosyl group in a $\left[\mathrm{Ru}(\mathrm{CN})_{5} \mathrm{NO}\right]^{3-}$ species. Measurements at Q-band made it possible to identify the perpendicular and parallel components of this species (Table 1). The $g$-tensor for the $\left[\mathrm{Ru}(\mathrm{CN})_{5} \mathrm{NO}\right]^{3-}$ species presents axial symmetry with $g_{\perp}>g_{/ /} \approx g_{\mathrm{e}}$. From the NO ${ }^{14} \mathrm{~N}$ hyperfine tensor we calculate $\mathrm{A}_{\text {iso }}=66.2 \mathrm{MHz}$ and $\mathrm{A}_{\text {aniso }}=5.5 \mathrm{MHz}$. Ratio between these values and those calculated considering one unpaired electron in a $2 \mathrm{~s}$ or in a $2 \mathrm{p}$ nitrogen orbital leads to unpaired electron densities 12 of $4.3 \%$ and $11.8 \%$ respectively. Recent calculations ${ }^{13}$ using Density Functional theory indicate that in this complex, as well as in the $\mathrm{Fe}$ analogous complex, the unpaired electron molecular orbital is primarily $\pi^{*}(\mathrm{NO})$ mixed with metal $\mathrm{d}_{\mathrm{xz}}$ and $\mathrm{d}_{\mathrm{yz}}$ orbitals. Measured g-values for both complexes qualitatively agree with this result as shown in Table 1. Unpaired electron spin densities on the NO nitrogen are also shown in Table 1. Higher spin-density values and lower g-values for the ruthenium species follow the larger $4 \mathrm{~d}$ wave-function delocalization.

Observation of I = 5/2 $99 \mathrm{Ru}$ ( $12.7 \%$ natural abundance) and ${ }^{101} \mathrm{Ru}(17 \%$ natural abundance) hyperfine interactions proved to be rather difficult. Besides the amorphous nature of samples, which broadens the ESR spectrum, lines corresponding to ruthenium isotopes are already broadened by a partial superposition due to a small difference in their magnetic moments 14 .

\section{The $\mathrm{NO}_{2}$ species}

ESR measurements as function of temperature allows the progressive observation of another set of triplets. Figure 1a shows the results at $5 \mathrm{~K}$. Hyperfine interaction is anisotropic, with $173.7 \mathrm{MHz}$ and $126.8 \mathrm{MHz}$ 
for perpendicular and parallel components, respectively. These values suggest the presence of a $\mathrm{NO}_{2}$ species, in agreement with the values reported in reference 15 for this radical. This species relaxes fast and can only be observed below $150 \mathrm{~K}$. For samples irradiated at $77 \mathrm{~K}$, only a small amount of $\mathrm{NO}_{2}$ is formed and $\left[\mathrm{Ru}(\mathrm{CN})_{5} \mathrm{NO}^{3-}\right.$ is the prevailing species. The single line at $g=2.0005$, less intense on samples irradiated at $77 \mathrm{~K}$, remains not identified.

Table 1. g-values, NO ${ }^{14} \mathrm{~N}$-hyperfine coupling constants and unpaired electron densities on nitrogen $2 \mathrm{~s}$ and $2 \mathrm{p}$ orbitals

\begin{tabular}{lcccccc}
\hline Species & $\mathrm{g}^{\wedge}$ & $\mathrm{g}_{/ /}$ & $\mathrm{A}^{\wedge \mathrm{a}}$ & $\mathrm{A}_{/ /}{ }^{\mathrm{a}}$ & $\mathrm{f}_{\mathrm{s}}(\%)$ & $\mathrm{f}_{\mathrm{p}}(\%)$ \\
\hline$\left[\mathrm{Ru}(\mathrm{CN})_{5} \mathrm{NO}\right]^{3-}$ & 2.0064 & 1.9990 & 60.7 & 77.3 & 4.3 & 11.8 \\
{$\left[\mathrm{Fe}(\mathrm{CN})_{5} \mathrm{NO}\right]^{3-\mathrm{b}}$} & 2.0355 & 2.0062 & 40.2 & 47.7 & 2.8 & 5.2 \\
\hline
\end{tabular}

a hyperfine interations in $\mathrm{MHz}$ units; ${ }^{\mathrm{b}}$ from ref. [5].

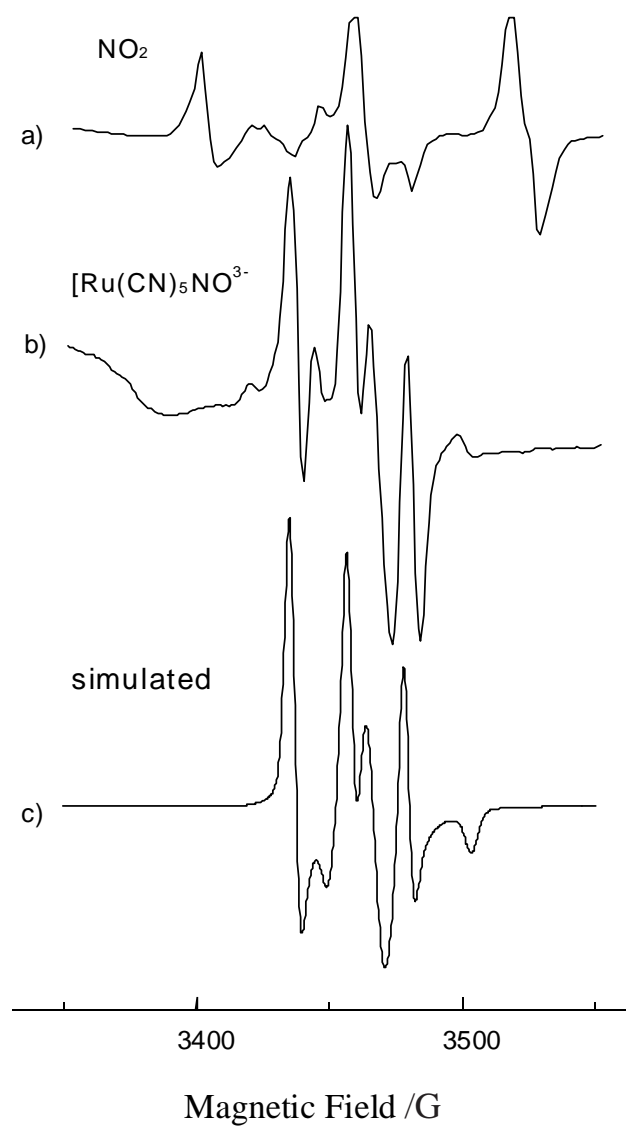

Figure 1. First derivative $X$-band ESR spectrum of $\mathrm{K}_{2}\left[\mathrm{Ru}(\mathrm{CN})_{5}\right.$ $\mathrm{NO}] . \mathrm{H}_{2} \mathrm{O}$ irradiated at room temperature for one $\mathrm{h}$ : (a) spectrum measured at $5 \mathrm{~K}$; (b) room temperature spectrum; (c) simulated room temperature spectrum.

\section{The $A g(0)$ centre}

Attempts to attribute the multiplets that flank the central spectrum, as described above, to a pair interaction, as reported in reduced sodium nitroprusside 5 , were not possible. On the other hand, X-rays analysis reveals the presence of $\mathrm{AgCl}$ crystals on the synthesized sample, suggesting that silver ions may be also present in the sample as an impurity. $\operatorname{Ag}(0)$ paramagnetic centres are reported in the literature16; g-values are close to the free electron value and hyperfine interaction with the $\mathrm{I}=1 / 2$ silver isotopes is about 600 Gauss and isotropic. Attempts to fit this part of the spectrum considering isotropic couplings to one $\operatorname{Ag}(0)$ and to four equivalent nitrogens improved the situation but still were not satisfactory. The best fit is obtained assuming a small rhombicity in the g-tensor and in silver hyperfine coupling, as shown in Table 2 and Figure 2. Fittings were performed in third order perturbation theory with the aid of Simfonia software, kindly supplied by Bruker-Physik. The amorphous nature of the sample precludes a better looking fitting, although line positions are very well reproduced; the reason for this is that line shapes for amorphous samples are not the same as for powdered samples, assumed by the software.

Table 2. Spin-hamiltonian parameters for the $\operatorname{Ag}(0)$ centre in various irradiated matrices

\begin{tabular}{lcccccc}
\hline Matrix & $\mathrm{A}_{\mathrm{x}}{ }^{\mathrm{a}, \mathrm{b}}$ & $\mathrm{A}_{\mathrm{y}}$ & $\mathrm{A}_{\mathrm{z}}$ & $\mathrm{g}_{\mathrm{x}}{ }^{\mathrm{a}}$ & $\mathrm{g}_{\mathrm{y}}$ & $\mathrm{g}_{\mathrm{z}}$ \\
\hline $\mathrm{H}_{2} \mathrm{O}(4.2 \mathrm{~K}){ }^{\mathrm{c}}$ & -630 & & & 2.001 & & \\
$\mathrm{MeCN}^{\mathrm{A}} \mathrm{AgNO}_{3}{ }^{\mathrm{d}}$ & -631 & & & 1.997 & & \\
$\mathrm{MeCN}_{\mathrm{AgClO}}{ }_{4}{ }^{\mathrm{e}}$ & $-538 \pm 2$ & & & 1.997 & & \\
$\mathrm{KCl}{ }^{\mathrm{f}}$ & -640 & & & 2.000 & & \\
& & & &
\end{tabular}

$\mathrm{Ru}(\mathrm{CN})_{5} \mathrm{NO} / \mathrm{AgCl}-638 \pm 2^{\mathrm{g}}-576 \pm 5-756 \pm 2 \quad 2.000^{\mathrm{g}} 1.9981 .980^{\mathrm{a}}$

If only the $\mathrm{x}$-component is quoted, the tensor is reported to be isotropic; ${ }^{b}{ }^{109} \mathrm{Ag}$ hyperfine interaction in Gauss $\left(1 \mathrm{G}=10^{-4} \mathrm{~T}=2.8 \mathrm{MHz}\right.$ if $\mathrm{g}=2.0023)$; ${ }^{\mathrm{R}}$ Ref. [17]; ${ }^{\mathrm{d}}$ Ref. [18]; ${ }^{\mathrm{R}}$ Ref. [16], $\mathrm{A}\left({ }^{14} \mathrm{~N}\right)=6.5 \pm 0.5 \mathrm{G}$; ${ }^{\mathrm{f}}$ Ref. [19]; gThis work; $\mathrm{A}_{\text {iso }}=-657 \pm 3, \mathrm{~g}_{\text {iso }}=1.993, \mathrm{~A}\left({ }^{14} \mathrm{~N}\right)=13.0 \pm 0.2 \mathrm{G}$.

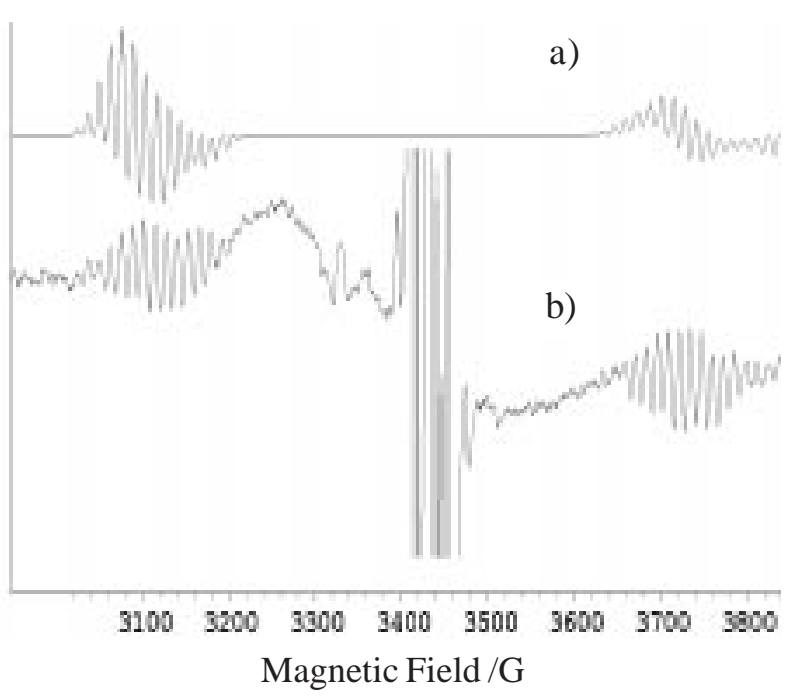

Figure 2. Comparison between room temperature first derivative $\mathrm{X}$-band ESR spectrum of the silver center (b) and powder spectrum simulation (a) taking into account silver isotopic composition, hyperfine interactions with four equivalent nitrogens and rhombicity as described in the text. The amorphous nature of samples is revealed in the experimental line shapes but not in the simulated powder spectrum. 
Table 2 also displays a review of $\operatorname{Ag}(0)$ data found in the literature. To our knowledge this is the first report on anisotropic $\operatorname{Ag}(0)$ ESR spectrum. Anisotropy may result from a mixture between silver $6 \mathrm{~s}$ orbital and $5 \mathrm{~d}$ orbitals, allowed by a low local symmetry. The four nitrogens appear to interact identically with the unpaired electron. The measured hyperfine interaction is assumed to be isotropic; its value is 13 Gauss, twice as large as found in reference 16, where coordination is postulated to be tetrahedral. This reinforces a non-tetrahedral coordination; participation of $\operatorname{Ag}(0) 5 \mathrm{~d}$ orbitals in the molecular orbital would increase unpaired electron density on the ligands.

\section{Acknowledgments}

This work was supported by $\mathrm{CNPq}$ (Conselho Nacional de Desenvolvimento Científico e Tecnológico), FUJB (Fundação José Bonifácio), FAPERJ (Fundação deAmparo à Pesquisa do Estado do Rio de Janeiro) and CEPG-UFRJ. We are indebted to C. A. Téllez Soto for FTIR spectra and to A. A. Leitão for useful discussions.

\section{References}

1. Bernal, I.; Hockings, E. F. Proc. Chem. Soc. 1962, 361.

2. McNeil, D. A. C.; Raynor, J. B.; Symons, M. C. R. J. Chem. Soc. 1965, 410.

3. van Voorst, J. D. W.; Hemmerich, P. J. Chem. Phys. 1966, 45, 3914.

4. Danon, J.; Muniz, R. P. A.; Panepucci, H. J. Chem. Phys. 1964, 41, 3651.
5. Goodman, B. A.; McNeil, D. A. C.; Raynor, J. B.; Symons, M. C. R. J. Chem. Soc. (A) 1966, 1547.

6. Symons, M. C. R.; West, D. X.;Wilkinson, J. G. Inorg. Chem. 1976, 15, 1022.

7. Fiedler, J. Collect. Czech. Chem. Commun. 1993, $58,461$.

8. Krause, R. A.; Violette, C. Inorg. Chim. Acta 1986, 113, 161.

9. Butler, A. R.; Calsy-Harrison, A. M.; Glidewell, C. R.; Johnson, I. L. Inorg. Chim. Acta 1988, 146, 18.

10. Olabe, J. A.; Gentil, L.A.; Rigotti, G.; Navaza,A. Inorg. Chem. 1984, 23, 4297.

11. Guenzburger, D.; Garnier, A.; Danon, J. Inorg. Chim. Acta 1977, 21, 119.

12. Hayes, R. G. in Electron Spin Ressonance of Metal Complexes, Teh Fu Yen Ed., Plenum Press 1969, p.23.

13. Gómes, J. A.; Guenzburger, D. Chem. Phys. 2000, 253, 73.

14. Vugman, N. V.; Livi, C. P.; Danon, J. Molec. Phys., 1982, 46, 1085.

15. Golding, R. M.; Henchman, M. J. Chem. Phys. 1964, 40, 1554.

16. Symons, M. C. R.; Brown, D. R.; Eastland, G. W. Chem. Phys. Lett. 1979, 61, 92.

17. Kevan, L.; Hase, H.; Kawabata, K. J. Chem. Phys. 1977, 66, 3834.

18. Brown, D. R.; Findlay, T. J. V.; Symons, M. C. R. J. Chem. Soc. Faraday Trans. 1 1976, 72, 1792.

19. Delbecq, C. J.; Hayes, W.; O’Brian, M. C. M.; Yuster, Y. N. Proc. Roy. Soc. 1963, 271, 243.

Received: September 13, 1999 